\title{
Practice, science and governance in interaction: European effort for the system-wide implementation of the International Classification of Functioning, Disability and Health (ICF) in Physical and Rehabilitation Medicine
}

\author{
Gerold STUCKI 1,2,3*, Mauro ZAMPOLINI 4, Alvydas JUOCEVICIUS 5, \\ Stefano NEGRINI 6, 7, Nicolas CHRISTODOULOU 8, 9, 10
}

\begin{abstract}
${ }^{1}$ Swiss Paraplegic Research (SPF), Nottwil, Switzerland; ${ }^{2}$ ICF Research Branch, a Cooperation Partner within the WHO Collaborating Centre for the Family of International Classifications in Germany (at DIMDI), Nottwil, Switzerland; ${ }^{3}$ Department of Health Sciences and Health Policy, Faculty of Humanities and Social Sciences, University of Lucerne, Lucerne, Switzerland; ${ }^{4}$ Department of Rehabilitation, USL Umbria 2, Foligno Hospital, Foligno, Perugia, Italy; ${ }^{5}$ Rehabilitation, Physical and Sport Medicine Center Department of Vilnius University Hospital Santariskiu Klinikos, Medical Faculty Vilnius University, Vilnius, Lithuania; ${ }^{6}$ Department of Clinical and Experimental Sciences, University of Brescia, Brescia, Italy; ${ }^{7}$ Don Gnocchi Foundation, Milan, Italy; ${ }^{8}$ European University Cyprus, Medical School, Nicosia, Cyprus; ${ }^{2}$ Limassol Centre of Physical and Rehabilitation Medicine NX, Limassol, Cyprus; ${ }^{10}$ President of the UEMS PRM Section
\end{abstract}

*Corresponding author: Gerold Stucki, Swiss Paraplegic Research (SPF), Guido A. Zäch Strasse 4, 6207, Nottwil, Switzerland. E-mail: gerold.stucki@paraplegie.ch

\section{A B S T R A C T}

Since its launch in 2001, relevant international, regional and national PRM bodies have aimed to implement the International Classification of Functioning, Disability and Health (ICF) in Physical and Rehabilitation Medicine (PRM), whereby contributing to the development of suitable practical tools. These tools are available for implementing the ICF in day-to-day clinical practice, standardized reporting of functioning outcomes in quality management and research, and guiding evidence-informed policy. Educational efforts have reinforced PRM physicians' and other rehabilitation professionals' ICF knowledge, and numerous implementation projects have explored how the ICF is applied in clinical practice, research and policy. Largely lacking though is the system-wide implementation of ICF in day-to-day practice across all rehabilitation services of national health systems. In Europe, system-wide implementation of ICF requires the interaction between practice, science and governance. Considering its mandate, the UEMS PRM Section and Board have decided to lead a European effort towards system-wide ICF implementation in PRM, rehabilitation and health care at large, in interaction with governments, non-governmental actors and the private sector, and aligned with ISPRM's collaboration plan with WHO. In this paper we present the current PRM internal and external policy agenda towards system-wide ICF implementation and the corresponding implementation action plan, while highlighting priority action steps - promotion of ICF-based standardized reporting in national quality management and assurance programs, development of unambiguous rehabilitation service descriptions using the International Classification System for Service Organization in Health-related Rehabilitation, development of Clinical Assessment Schedules, qualitative linkage and quantitative mapping of data to the ICF, and the cultural adaptation of the ICF Clinical Data Collection Tool in European languages.

(Cite this article as: Stucki G, Zampolini M, Juocevicius A, Negrini S, Christodoulou N. Practice, science and governance in interaction: European effort for the system-wide implementation of the International Classification of Functioning, Disability and Health (ICF) in Physical and Rehabilitation Medicine. Eur J Phys Rehabil Med 2017;53:299-307. DOI: 10.23736/S1973-9087.16.04436-1)

Key words: Physical and rehabilitation medicine - International Classification of Functioning, Disability and Health - Physicians. 


\section{COPYRIGHT $^{(} 2017$ EDIZIONI MINERVA MEDICA}

$\mathrm{I}^{\mathrm{n}}$ 2001, the World Health Assembly (WHA) endorsed the International Classification of Functioning, Disability and Health (ICF). ${ }^{1}$ The launch of the ICF was a landmark event for rehabilitation. ${ }^{2,3}$ This is because for rehabilitation "the ICF serves as a practical lens through which we can observe the lived experience of health in a way that is meaningful and useful to practitioners who aim to optimize functioning of individual patients, policy makers who aim to shape the health system in response to persons' functioning needs, and researchers who aim to explain and influence functioning". ${ }^{3}$

Consequently, since the launch of ICF, relevant Physical and Rehabilitation Medicine (PRM) bodies at the international, regional and national level have aimed to implement the ICF in PRM. First and foremost is the application of the ICF in the definition of the PRM specialty. Thus, in 2011 the umbrella organization of PRM physicians worldwide, the International Society of Physical and Rehabilitation Medicine (ISPRM), endorsed an ICF-based conceptual description of PRM, understood as the "Medicine of Functioning", ${ }_{4}$ as well as an ICF-based conceptual description of rehabilitation, understood as a health strategy in conjunction with prevention and cure. ${ }^{5}$ Both conceptual descriptions were developed based on the responses to two discussion papers published in 2007 on behalf of the Professional Practice Committee of the European Union of Medical Specialists (UEMS) PRM Section.6, 7 The conceptual descriptions endorsed by ISPRM have served as the basis for other conceptual descriptions e.g. for specific applications like vocational rehabilitation. ${ }^{8}$ Based on these ICF-based conceptual descriptions, rehabilitation aims to optimize peoples' functioning and to minimize the experience of disability.

ISPRM has also been instrumental in the development of practical tools necessary for the application of the ICF in rehabilitation practice, research and policy. Based on a decision taken by the ISPRM Assembly of Delegates during its first congress in 2001 in Amsterdam ${ }^{9}$ ISPRM spearheaded the application of the ICF by leading the effort to develop ICF Core Sets, standards for the application of the ICF in rehabilitation and health care at large. ${ }^{10-13}$ Collaborating with the World Health Organization (WHO), ISPRM also contributed to the development of the so-called 'func- tioning properties' that will be introduced into the $11^{\text {th }}$ revision of the International Classification of Diseases (ICD-11) to describe the potential impact of a specific disease/disorder on a person's functioning, and hence will allow for the coding of functioning e.g. in the context of diagnosis-related groups (DRGs). ${ }^{14-16}$ Responding to an initiative by the Chinese Association for PRM (CARM) ${ }^{17}$ to develop a simple ICF Clinical Data Collection Tool as a "default assessment tool" for rehabilitation and health care at large, ISPRM, supported by the Italian Society of PRM (SIMFER), is now collaborating with the Asian-Oceanian Society of PRM, the UEMS PRM Section and Board, and national PRM societies in its cultural adaptation worldwide. These practical tools allow for the implementation of the ICF in day-to-day clinical practice, the standardized reporting of functioning outcomes in both quality management and research, and for guiding evidenceinformed policy.

Parallel to the developments of practical tools major educational initiatives ${ }^{18-21}$ have reinforced the ICF knowledge of PRM physicians and other rehabilitation professionals, and numerous implementation projects have explored how to apply the ICF in clinical practice, research and policy. ${ }^{22,23}$ What is still largely lacking, however, is the full and systematic integration of the ICF in day-to-day practice across all rehabilitation services of national health systems, that is, its systemwide implementation.

In Europe, the system-wide implementation of the ICF in day-to-day rehabilitation practice requires a concerted effort and interaction between practice, science and governance. Considering its mandate in the field of competence of PRM specialists, the UEMS PRM Section and Board has decided to lead a European effort towards the system-wide implementation of the ICF in PRM, rehabilitation and health care at large in interaction with governments, non-governmental actors and the private sector. The effort is aligned with ISPRM's work plan with WHO.

In this paper we present the leadership role of the UEMS PRM Section and Board, the emerging internal and external policy agenda and the implementation action plan towards the system-wide implementation of the ICF in PRM, rehabilitation and health care at large. 


\section{COPYRIGHT $^{(} 2017$ EDIZIONI MINERVA MEDICA}

IMPLEMENTATION OF THE ICF IN PRM

\section{The leadership role of the UEMS PRM Section and Board}

Recognizing the opportunities and overcoming the challenges arising from the system-wide implementation of the ICF is primarily a matter of governance. Governance in this context relates to the role of a nongovernmental actor such as the UEMS PRM Section and Board in the specification of norms within its field of competence and in cooperation with other medical specialties, governments, other non-governmental actors, and the private sector.

Figure 1 shows how the UEMS with its Sections, including the PRM Section, provides advice to the European Commission for primary legislation and participates in committees for the implementation of directives. It is in contact with members of the European Parliament, and through its national member associations, UEMS cooperates with national governments and provides advice to the European Council. Through these policy channels the UEMS PRM Section and Board has the capacity to advocate for the system-wide implementation of the ICF not only in PRM, but also in other areas of rehabilitation and health care at large. Thus, the UEMS PRM Section and Board is ideally positioned to lead the efforts in the system-wide implementation of the ICF in PRM, rehabilitation and health care at large in interaction with governments, non-governmental actors and the private sector.

Against this backdrop, the assembly of the UEMS PRM Section and Board decided at its meeting in St. Petersburg (3-5 September 2015) to initiate a European effort with the goal of the "system wide implementation of the ICF in PRM, envisioning its implementation in rehabilitation and health care at large". The effort is being led by the Presidents of the UEMS Section and Board (NC, AJ) and coordinated by its Secretary General (MZ) and its Expert for the ICF (GS), and involves the Clinical Affairs and the Professional Practice Committee as well as the entire UEMS PRM Board. To develop an implementation action plan a workshop was held in Nottwil, Switzerland, from 22-23 January 2016, and hosted by the Swiss Society of PRM (SGPMR) and the Swiss Paraplegic Foundation. The implementation action plan was presented, reviewed and updated in the meeting of the UEMS PRM Section and Board in Athens from 25-27 February 2016.

To strengthen its effort, the UEMS PRM also collaborates with its national member organizations and ISPRM according to their mutual recognition agree-

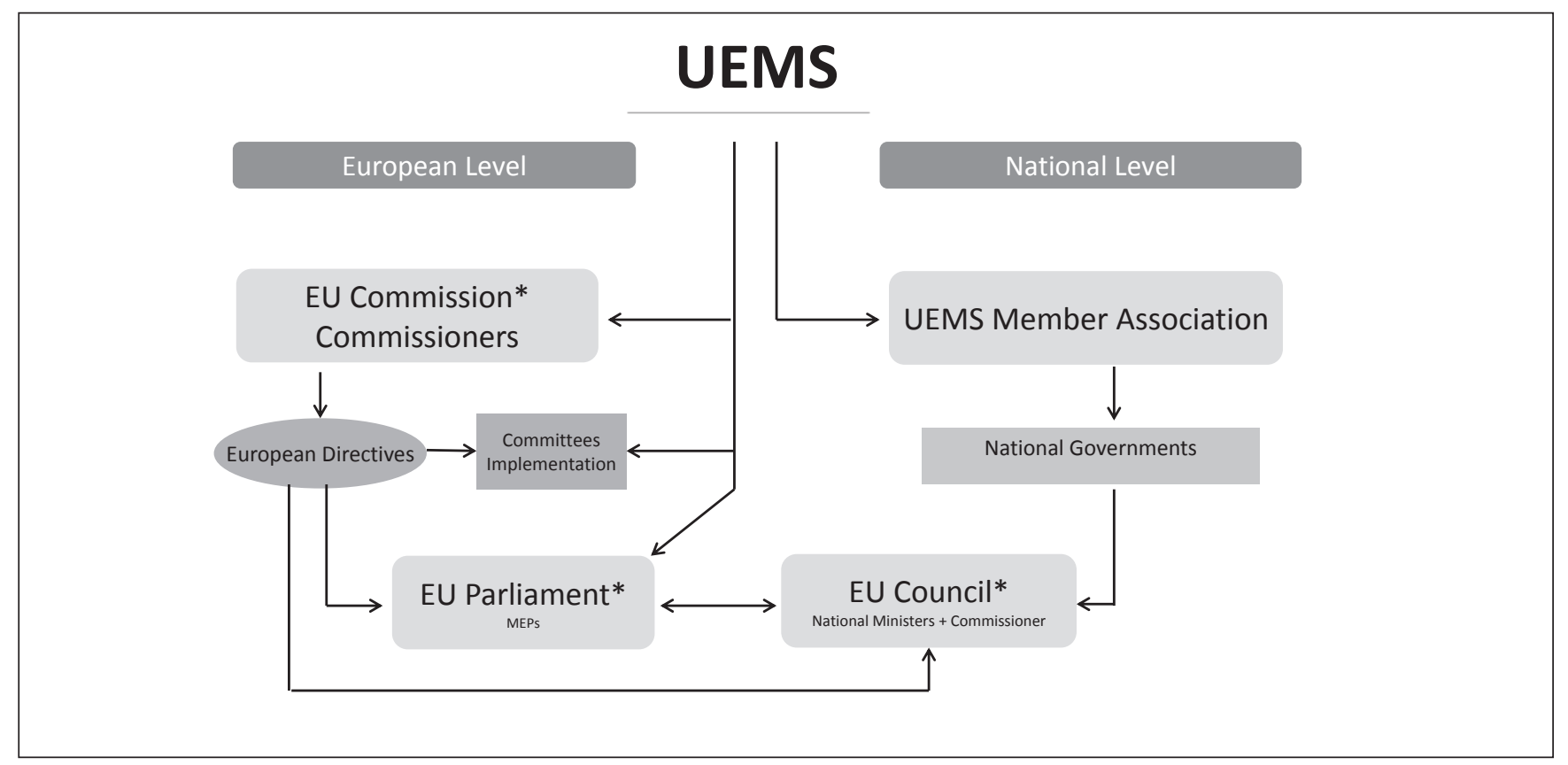

Figure 1.-Organogram UEMS. 


\section{COPYRIGHT $^{(} 2017$ EDIZIONI MINERVA MEDICA}

ment. ${ }^{24}$ The basis for the current collaboration is the ISPRM-WHO collaboration plan 2015-2017 25 with a focus on the implementation of WHO's Global Disability Action Plan 2014-2021.26, 27 Item 3 of the ISPRMWHO collaboration plan calls for national models for ICF-based routine data collection and national rehabilitation quality management programs that aim to strengthen the disability component in national health information systems. ${ }^{26}$ These two concrete goals provide the concrete reference point for the European effort towards the system-wide implementation of the ICF.

\section{Internal policy agenda within the field of competence of PRM specialists}

\section{Promoting the use of ICF by PRM specialists}

Two related barriers towards the system-wide implementation of ICF in daily PRM practice are misconceptions and its perceived complexity. One misconception to be corrected is the view that the ICF is just another outcome measure. What needs to be promoted is the understanding and use of the ICF as a health information reference. The ICF is not a measure but a reference classification and standard. ${ }^{3}$ To overcome the perception that the ICF is too complex to implement in day-to-day practice, we need to foster the view that the ICF is a powerful lens through which we can observe, understand and influence people's lived experience. In turn it can guide clinical decision-making and outcome evaluation and most importantly, its use, facilitated by the now available range of suitable tools, such as the ICF Core Sets, is fundamental for rehabilitation practice and not an additional time-consuming activity. For example, the ICF is ideally suited for the standardized reporting of rehabilitation goals. With respect to assessment, the Chinese slogan "simple is best" may provide an important lesson - the ICF Clinical Data Collection Tool developed by CARM and tested for the European cultural context by the SIMFER may be the most promising tool for assessing functioning across rehabilitation and health services of the health care system. ${ }^{28}$

\section{Entrenching the ICF in the field of competence of PRM specialists}

The most important document in defining the field of competence of PRM specialists is the White book on Physical and Rehabilitation Medicine in Europe developed in a collaborative effort of the UEMS PRM Section and Board with the European Society of PRM and the European Academy of PRM. ${ }^{29}$ The currently planned revision of the White book provides the unique opportunity to embed information about the ICF implementation in the White book chapters where appropriate, thus entrenching ICF implementation in the field of competence of PRM specialists.

\section{ICF-based outcome evaluation in quality management and accreditation of rehabilitation services}

In the future the application of the ICF in rehabilitation service provision may become an essential aspect of rehabilitation service accreditation. More concretely, the accreditation process may examine whether and how an ICF-based measurement-for-improvement system has been integrated in rehabilitation quality management of a service is used for clinical decision-making, and has contributed to continuous improvement of service outcome.

The concrete steps necessary to integrate the ICF in rehabilitation service provision are discussed further in the section "Implementation governance challenges at the level of service and care provision" since this is as much an external as well as a PRM internal policy agenda item.

Beyond PRM: external policy agenda in interaction with the health care system

\section{Implementation governance challenges at the European and national policy level}

The first implementation governance challenge faced is at the macro-level of European and national policy. Here the goal is to advocate for the inclusion of the ICF and ICF-based standards for data collection and reporting in the six components of national health systems including health information, service delivery, financing and work force. ${ }^{30}$

To reach this goal the UEMS PRM Section and Board could elicit the support of other UEMS Sections representing medical specialties with an interest in functioning and rehabilitation. This is highly relevant since the success of system-wide ICF implementation not only depends on the leadership of PRM, but ultimately relies on the support of other medical specialties and health professions involved in rehabilitation and disability 


\section{COPYRIGHT $^{\odot} 2017$ EDIZIONI MINERVA MEDICA}

management. One may even argue that the successful implementation of the ICF in PRM can only be achieved with the successful implementation of the ICF in national health systems at large. This insight is reflected in the European effort goal that explicitly extends ICF implementation beyond PRM, envisioning its implementation in rehabilitation and health care at large.

\section{Implementation governance challenges at the National Quality Management level}

The second implementation governance challenge is at the meso-level of national rehabilitation quality management against the backdrop of macro-level policies. To address this challenge we first have to develop an approach on how to design and implement a national rehabilitation quality management system in alignment with the micro-level ICF-based rehabilitation quality management approach described below. Moreover, strategies for aligning ICF-based national rehabilitation quality management systems with existing quality management and quality assurance systems in the rehabilitation sector and health care at large must be developed.

In the context of the European effort toward systemwide implementation of the ICF first steps to develop a model for a national rehabilitation quality management, including a data collection architecture, criteria for IT solutions and solutions for data protection, have been taken. In this effort, the UEMS PRM Section and Board has initiated a collaboration with the Japanese Association of PRM (JARM), who has embarked on a project to develop a national rehabilitation quality management system based on an existing registry. ${ }^{31}$

\section{Implementation Governance Challenges at the care provision level}

The third implementation governance challenge is at the level of care provision. Clinical leaders are faced with the challenge of implementing the ICF in dayto-day clinical practice at the micro-level, while also ensuring continuous quality improvement at the mesolevel of rehabilitation services and adhering to the requirements at the national level. The construction of an ICF-based clinical quality management program that is useful for both the management of individual patients as well as improvement of rehabilitation service quality, is driven by several action steps.
First, it requires the unambiguous description of a service. To ensure recognition by patients, payers and policy makers, a description of a service should include a short narrative description in lay language. To minimize ambiguity and ensure comparability of rehabilitation services a description should include a systematic, classification-based description e.g. by applying the International Classification System for Service Organization in Health-related Rehabilitation (ICSO-R). ${ }^{32}$ Methods for developing such narrative and classification-based descriptions were explored in the aforementioned Nottwil workshop for 6 exemplary rehabilitation services and are reported in Kiekens et al. ${ }^{33}$ Based on the deliberations at the Feb. 2016 Athens meeting, developing descriptions for at least 10 rehabilitation services that represent the innovative spectrum of rehabilitation services throughout Europe is envisioned.

The second action step is the specification of a socalled Clinical Assessment Schedule. A Clinical Assessment Schedule specifies what ICF domains to document (compulsory and optional). Methods for developing a clinical assessment schedule was also explored in the Nottwil workshop using the aforementioned 6 rehabilitation services. The results are presented in Prodinger et al. ${ }^{34}$ As with the rehabilitation services descriptions, there is a plan to develop clinical assessment schedules for at least 10 reference rehabilitation services throughout Europe.

The third action step is the ICF-based standardized documentation of functioning with data collected in clinical routine. This entails the qualitative linking and quantitative mapping of data collected with the a range of currently available data collection tools to the ICF. Qualitative linking involves linking concepts contained in the data collected to the ICF following established linking rules. ${ }^{35}$ To determine the metric equivalence of items or sub-scales of the data collection tools, the items/ sub-scales that cover the domain defined by the linked ICF categories are then quantitatively mapped using the Rasch methodology. The resulting Rasch scores can then be compared on a common metric. This methodology was presented at the Nottwil workshop as well. ${ }^{36,37}$

A universal alternative to the use of current data collection tools is the use of the newly developed ICF Clinical Data Collection Tool which is based on simple intuitive descriptions and uses a Numerical Rating Scale. ${ }^{38}$ This tool has been developed in an international coop- 


\section{COPYRIGHT $^{(} 2017$ EDIZIONI MINERVA MEDICA}

STUCKI

IMPLEMENTATION OF THE ICF IN PRM

TABLE I.-ICF Implementation Action Plan.

\begin{tabular}{|c|c|c|c|}
\hline Topic & Activity & Deliverable & Comment \\
\hline \multicolumn{4}{|c|}{ ICF in Data Collection } \\
\hline $\begin{array}{l}\text { ICF Clinical Data } \\
\text { Collection Tool }\end{array}$ & $\begin{array}{l}\text { National consensus conferences to } \\
\text { develop language-specific versions } \\
\text { following a protocol established by } \\
\text { SIMFER in collaboration with the } \\
\text { ICF Research Branch } 28 \\
\text { Cooperation across national societies } \\
\text { for the development of a language- }\end{array}$ & $\begin{array}{l}\text { Publication of the language-specific } \\
\text { versions in a joint publication }\end{array}$ & $\begin{array}{l}\text { Hosting of the language versions of the ICF } \\
\text { Clinical Data Collection Tool on the webpages } \\
\text { of the relevant national societies, the UEMS } \\
\text { PRM Section and Board (www.euro-prm. } \\
\text { org) and the ICF Research Branch (www.icf- } \\
\text { research-branch.org) }\end{array}$ \\
\hline
\end{tabular}

Scoring algorithms for the ICF components body functions $\&$ structures and activity \& participation specific versions spoken in several European countries (e.g. French, Dutch)

Development of scoring algorithms using Rasch analysis based on a European-wide data collection effort applying the language-specific versions of the ICF Clinical Data Collection Tool

ICF in Rehabilitation Services

\section{Development of unambiguous narrative and classification-based descriptions of specific rehabilitation services by applying ICSO-R 32,33}

Identification of comparable rehabilitation services across Europe

List of descriptions of specific rehabilitation services in Europe

List of similar rehabilitation services that are used across Europe along the continuum of care (acute, post-acute, long-term)

Specification of Clinical Assessment Schedules for specific rehabilitation services using a protocol currently in development ${ }^{34}$

Development of measurement-forimprovement systems for clinical decision- making in individual patients (micro-level) and continuous improvement of a rehabilitation service (meso-level)

ICF in Data Reporting

Existing data collection tools

Identification of data collection tools that cover the ICF domains included in the Clinical Assessment Schedules of specific rehabilitation services

Review of data collection tools identified in a European- wide project called "European Standardization of Outcome Measurement in Rehabilitation" (Pro-ESOR) ${ }^{42,43}$
Implemented Clinical Assessment Schedules for specific rehabilitation services

Implementation of measurementfor-improvement systems in

List of data collection tools that cover the ICF domains included in the Clinical Assessment Schedule of specific rehabilitation services

List of data collection tools described in Pro-ESOR that are well-known, considered valid and are currently used in clinical practice rehabilitation services across Europe
Development of a European portfolio of model rehabilitation services (prototypical descriptions) and reference rehabilitation services (real life examples)

Designation of a reference rehabilitation service based on defined criteria (established measurement-for-improvement system; leaders of the service willing to take on the role of "knowledge brokers" by sharing their expertise with colleagues and providing advice to policymakers from different European countries)

Clinical Assessment Schedules for services along the continuum of care can be combined meaningfully in national reference models for rehabilitation quality management

Potential for integrating a measurement-forimprovement system with a "measurementfor-research" system e.g. cohort studies, clinical registries and clinical trials

The list of data collection tools will grow with the number of Clinical Assessment Schedules

This list will enrich the list of data collection tools that cover the Clinical Assessment Schedule domains 


\section{COPYRIGHT ${ }^{\odot} 2017$ EDIZIONI MINERVA MEDICA}

IMPLEMENTATION OF THE ICF IN PRM

TABLE I.-ICF Implementation Action Plan (continues).

\begin{tabular}{|c|c|c|c|}
\hline Topic & Activity & Deliverable & Comment \\
\hline $\begin{array}{l}\text { ICF-based reporting } \\
\text { of data }\end{array}$ & $\begin{array}{l}\text { Qualitative linking and quantitative } \\
\text { mapping of data collected with the } \\
\text { tools identified above to the ICF } \\
\text { using the methodology developed in } \\
\text { the ICF INFO project } 37,44\end{array}$ & $\begin{array}{l}\text { Tables displaying ICF domains } \\
\text { resulting from the qualitative linking } \\
\text { of data collection tools } \\
\text { Transformation tables using a } 0-100 \\
\text { interval reference scale that resulted } \\
\text { from the quantitative mapping } \\
\text { of data collected with the data } \\
\text { collection tools to the ICF }\end{array}$ & $\begin{array}{l}\text { Only data collection tools that fulfill three } \\
\text { criteria should be considered for quantitative } \\
\text { mapping: 1) extensively used in daily practice; } \\
\text { 2) well-known and considered valid by } \\
\text { experts; 3) available and validated in various } \\
\text { European languages } \\
\text { Hosting of the qualitatively linked and } \\
\text { quantitatively mapped data collection tools } \\
\text { on the webpages of the relevant national } \\
\text { societies, the UEMS PRM Section and Board } \\
\text { (www.euro-prm.org) and the ICF Research } \\
\text { Branch (www.icf-research-branch.org) }\end{array}$ \\
\hline \multicolumn{4}{|c|}{ ICF in National Rehabilitation Quality Management } \\
\hline & $\begin{array}{l}\text { Promotion of ICF-based standardized } \\
\text { reporting of functioning outcomes to } \\
\text { national quality agencies responsible } \\
\text { for quality management in } \\
\text { rehabilitation and health care at large }\end{array}$ & $\begin{array}{l}\text { Implementation of ICF-based } \\
\text { standardized reporting of functioning } \\
\text { outcomes within national quality } \\
\text { management agency programs }\end{array}$ & $\begin{array}{l}\text { This is an opportunity for PRM to promote } \\
\text { the ICF as a health information reference in } \\
\text { national health systems }\end{array}$ \\
\hline & $\begin{array}{l}\text { Cooperation with the International } \\
\text { Society of Physical and } \\
\text { Rehabilitation Medicine (ISPRM) } \\
\text { and the Japanese Association of } \\
\text { PRM (JARM) in the development of } \\
\text { a model data architecture for national } \\
\text { rehabilitation registries }\end{array}$ & $\begin{array}{l}\text { Availability of a model data } \\
\text { architecture for the development of } \\
\text { national rehabilitation registries }\end{array}$ & \\
\hline & $\begin{array}{l}\text { Development of IT and data protection } \\
\text { solutions }\end{array}$ & $\begin{array}{l}\text { Exemplary IT and data protection } \\
\text { solutions }\end{array}$ & \\
\hline \multicolumn{4}{|c|}{ ICF in the Accreditation of Rehabilitation Services } \\
\hline & $\begin{array}{l}\text { Development of criteria for the } \\
\text { accreditation of ICF-based } \\
\text { measurement-for-improvement } \\
\text { systems that complement the current } \\
\text { UEMS criteria for quality assurance }\end{array}$ & $\begin{array}{l}\text { Document outlining the criteria } \\
\text { for ICF-based measurement-for- } \\
\text { improvement systems }\end{array}$ & $\begin{array}{l}\text { The development of criteria for ICF-based } \\
\text { measurement-for-improvement systems may } \\
\text { lead to an update of the UEMS Section criteria } \\
\text { for rehabilitation services }\end{array}$ \\
\hline \multicolumn{4}{|c|}{ ICF in the Health Care System at Large } \\
\hline & $\begin{array}{l}\text { Cooperation between the UEMS PRM } \\
\text { Section and Board with the whole } \\
\text { UEMS in using the policy channels } \\
\text { described in Figure } 1\end{array}$ & $\begin{array}{l}\text { The UEMS supports the UEMS PRM } \\
\text { Section and Board in its effort to } \\
\text { implement the ICF and ICF based } \\
\text { standards, specifically the health } \\
\text { information component, in medicine } \\
\text { and the health care system at large }\end{array}$ & $\begin{array}{l}\text { In implementing the ICF in health systems } \\
\text { throughout Europe the leadership of the } \\
\text { UEMS PRM Section and Board may inspire } \\
\text { other medical specialties to use the ICF } \\
\text { as a health information reference for the } \\
\text { standardized reporting of health outcomes }\end{array}$ \\
\hline
\end{tabular}

eration under the auspices of ISPRM and in cooperation with the ICF Research Branch, a cooperation partner within the WHO Collaborating Center for Family of International Classifications in Germany. The first version was developed by CARM. ${ }^{17,} 39$ A second version, including its process for the cultural adaptation of the tool in European languages, was developed by SIMFER in collaboration with the ICF Research Branch. ${ }^{40,41}$ As part of the European effort for the system-wide implementation of the ICF, European language-specific versions will be developed and published. At the Nottwil workshop there was also agreement to develop scoring algorithms for the ICF Clinical Data Collection Tool that would allow the use of scores for clinical follow-up and outcome evaluation.

\section{ICF implementation action plan}

The ICF implementation action plan that resulted from discussions of the internal and external policy agenda items clearly shows that the system-wide implementation of the ICF in PRM requires a multi-faceted effort. Currently envisioned activities and deliverables are summarized in Table I. $28,32-34,37,42-44$ They are not 


\section{COPYRIGHT $^{(} 2017$ EDIZIONI MINERVA MEDICA}

set in stone but must be adjusted along the way as we learn what works and what does not work. At this stage the number of services ultimately needed to adequately describe the innovative spectrum of rehabilitation services across Europe still needs to be determined. Similarly, the data collection tools that are currently used and considered both useful and valid will only be identified once the action plan has progressed. The action plan will have important consequences with respect to the human and time resources needed for qualitative and quantitative cross-mappings.

\section{Conclusions}

At its core the system-wide implementation of the ICF in PRM, rehabilitation and the health care system at large requires the introduction of ICF-based standardized reporting of data collected with various data collection tools and the integrative use of these data for clinical practice, clinical and national quality management as well as outcomes and epidemiological research. This represents important changes to current practice at all levels.

Thus, for system-wide implementation of the ICF to be successful an unprecedented interaction between practice, science and governance is crucial. From the so-called "theory of change" $45-48$ we can learn that to succeed we need "champions" and "knowledge brokers". Champions are highly credible and convincing advocates of the cause at the European, national and local level. Champions we find in delegates of national PRM societies, their network of PRM specialists and patient advocates. Knowledge brokers are those who have unique expertise that they are willing to share. The knowledge brokers in our European effort are the colleagues who spearheaded the work on developing the conceptual description of rehabilitation services, including the specification of a Clinical Assessment Schedule and the construction and application of a measurement-for-improvement system for continuous quality improvement.

Finally, the UEMS PRM Section and Board's endeavor to bring together practice, science and governance would be empowered if other European PRM organizations, including the European Society of PRM and the European Academy of PRM, would join the effort. Indeed, the European effort towards the system- wide implementation of the ICF in PRM, rehabilitation and the health care system at large provides the three European organizations with a unique opportunity to collectively strengthen rehabilitation and the specialty of PRM in national health systems.

\section{References}

1. World Health Organization. The International Classification of Functioning, Disability and Health. Geneva: WHO Press; 2001.

2. Stucki G, Ewert T, Cieza A. Value and application of the ICF in rehabilitation medicine. Disabil Rehabil 2002;24:932-8.

3. Stucki G. The Olle Höök Lectureship 2015:The World Health Organization's Paradigm Shift and Implementation of the International Classification of Functioning, Disability and Health in Rehabilitation. J Rehabil Med 2016;48:486-93.

4. Gutenbrunner C, Meyer T, Melvin J, Stucki G. Towards a conceptual description of Physical and Rehabilitation Medicine. J Rehabil Med 2011;43:760-4.

5. Meyer T, Gutenbrunner C, Bickenbach J, Cieza A, Melvin J, Stucki G. Towards a conceptual description of rehabilitation as a health strategy. J Rehabil Med 2011;43:765-9.

6. Stucki G, Cieza A, Melvin J. The International Classification of Functioning, Disability and Health (ICF):A unifying model for the conceptual description of the rehabilitation strategy. J Rehabil Med 2007;39:279-85

7. Stucki G, Melvin J. The International Classification of Functioning, Disability and Health:A unifying model for the conceptual description of physical and rehabilitation medicine. J Rehabil Med 2007;39:286-92.

8. Escorpizo R, Reneman MF, Ekholm J, Fritz J, Krupa T, Marnetoft SU, et al. A conceptual definition of vocational rehabilitation based on the ICF: Building a shared global model. J Occup Rehabil 2011;21:12633.

9. Stucki G, Reinhardt JD, DeLisa JA, Imamura M, Melvin JL. Chapter 1:Achievements and challenges of ISPRM. J Rehabil Med 2009;41:791-7.

10. Stucki G, Kostanjsek N, Ustun B, Cieza A. ICF-based classification and measurement of functioning. Eur J Phys Rehabil Med 2008;44:315-28.

11. Bickenbach J, Cieza A, Rauch A, Stucki G. ICF Core Sets. Manual for Clinical Practice. Göttingen: Hogrefe; 2012.

12. ICF Based Documentation Form; 2016 [Internet]. Available from: https://www.icf-core-sets.org/ [cited 2016, July 19].

13. ICF Research Branch; 2016 [Internet]. Available from: https://www. icf-research-branch.org/ [cited 2016, July 19].

14. Kostanjsek N, Rubinelli S, Escorpizo R, Cieza A, Kennedy C, Selb $\mathrm{M}$, et al. Assessing the impact of health conditions using the ICF. Disabil Rehabil 2011:33:1475-82.

15. Escorpizo R, Kostanjsek N, Kennedy C, Nicol MM, Stucki G, Ustun TB. Harmonizing WHO's International Classification of Diseases (ICD) and International Classification of Functioning, Disability and Health (ICF): Importance and methods to link disease and functioning. BMC Public Health 2013;13:742.

16. Selb M, Kohler F, Robinson Nicol MM, Riberto M, Stucki G, Kenned C, et al. ICD-11:A comprehensive picture of health, an update on the ICD-ICF joint use initiative. J Rehabil Med 2015;47:2-8.

17. Prodinger B, Reinhardt JD, Selb M, Stucki G, Yan T, Zhang X, et al. Towards system-wide implementation of the International Classification of Functioning, Disability and Health (ICF) in routine practice: Developing simple, intuitive descriptions of ICF categories in the ICF Generic and Rehabilitation Set. J Rehabil Med 2016;48:508-14

18. Bornbaum CC, Day AM, Izaryk K, Morrison SJ, Ravenek MJ, Sleeth LE, et al. Exploring use of the ICF in health education. Disabil Rehabil 2015;37:179-86. 


\section{COPYRIGHT ${ }^{\odot} 2017$ EDIZIONI MINERVA MEDICA}

19. Francescutti C, Fusaro G, Leonardi M, Martinuzzi A, Sala M, Russo E, et al. Italian ICF training programs: describing and promoting human functioning and research. Disabil Rehabil 2009;31 Suppl 1:S46-9.

20. Geertzen JH, Rommers GM, Dekker R. An ICF-based education programme in amputation rehabilitation for medical residents in the Netherlands. Prosthet Orthot Int 2011;35:318-22.

21. Stucki G. Developing human functioning and rehabilitation research. Part I:Academic training programs. J Rehabil Med 2007;39:323-33.

22. Jelsma J. Use of the International Classification of Functioning, Disability and Health: A literature survey. J Rehabil Med 2009;41:1-12.

23. Cerniauskaite M, Quintas R, Boldt C, Raggi A, Cieza A, Bickenbach JE, et al. Systematic literature review on ICF from 2001 to 2009:Its use, implementation and operationalisation. Disabil Rehabil 2011;33:281-309.

24. Stucki G, Reinhardt JD, von Groote PM, DeLisa JA, Imamura M, JL. M. Chapter 2: ISPRM's way forward. J Rehabil Med 2009;41:798-809.

25. World Health Organization (WHO) and International Society of Physical and Rehabilitation Medicine (ISPRM). WHO-ISPM Collaboration Plan 2015-2017. Unpublished document. 2015.

26. Gutenbrunner C, Negrini S, Kiekens C, Zampolini M, Nugraha B. The Global Disability Action Plan 2014-2021 of the World Health Organisation (WHO): A major step towards better health for all people with disabilities. Chance and challenge for Physical and Rehabilitation Medicine (PRM). Eur J Phys Rehabil Med 2015;51:1-4.

27. World Health Organization. WHO global disability action plan 2014 2021; [Internet]. Available from: http://www.who.int/disabilities/actionplan/en/ [cited 2016 July 19].

28. Selb M, Gimigliano F, Prodinger B, Stucki G, Pestelli G, Iocco M, et al. Toward an International Classification of Functioning, Disability and Health clinical data collection tool: The Italian experience of developing simple, intuitive descriptions of the Rehabilitation Set categories. Eur J Phys Rehabil Med 2016 Nov 8 [Epub ahead of print].

29. Gutenbrunner C, Ward AB, Chamberlain MA (Eds). White Book of physical and rehabilitation medicine in Europe. Europa Medicophysica 2006;43:289-332.

30. Hopfe M, Prodinger B, Bickenbach J, Cieza A, Stucki G. Optimizing existing health systems: An argument for integrating functioning information. BMC Health Serv Res 2014;14:56.

31. Mukaino M, Saitoh E, Sonoda S, Yamada S, Mizuma M, Izumi ST. The Japanese experience in the development of national rehabilitation quality management systems. Oral presentation at the 10th International Society of Physical and Rehabilitation Medicine (ISPRM) World Congress, 2016 May 30, Kuala Lumpur, Malaysia.

32. Gutenbrunner C, Bickenbach J, Kiekens C, Meyer T, Skempes D, Nugraha B, et al. ISPRM discussion paper: Proposing dimensions for an International Classification System for Service Organization in Health-related Rehabilitation. J Rehabil Med 2015;47:809-15

33. Kiekens C, Meyer T, Gimigliano F, Baffone C, Gutenbrunner CMW. UEMS PRM Workshop report: Application of an International Classification System for Service Organization in Healthrelated Rehabilitation for describing rehabilitation services. Eur J Phys Rehabil Med 2016 Nov 24 [Epub ahead of print].

34. Prodinger B, Scheel-Sailer A, Escorpizo R, Stucki G. UEMS PRM
Workshop report: Toward the development of Clinical Assessment Schedules for specified rehabilitation services Eur J Phys Rehabil Med 2016 Nov 24 [Epub ahead of print].

35. Cieza A, Fayed N, Bickenbach J, Prodinger B. Refinements of the ICF Linking Rules to strengthen their potential for establishing comparability of health information. Disabil Rehabil 2016 Mar 17:1-10 [Epub ahead of print]

36. Prodinger B, Ballert CS, Brach M, Brinkhof MWG, Cieza A, Hug $\mathrm{K}$, et al. Special Issue SwiSCI: Toward standardized reporting for a cohort study on functioning: The Swiss Spinal Cord injury Cohort Study. J Rehabil Med 2016;48:189-96.

37. Prodinger B, Stamm T, Peterson D, Stucki G, Tennant A. Toward a Standardized Reporting of Outcomes in Hand Osteoarthritis: Developing a Common Metric of Outcome Measures Commonly Used to Assess Functioning. Arthritis Care Res 2016;68:1115-27.

38. Li J, Prodinger B, Reinhardt JD, Stucki G. Towards the system-wide implementation of the International Classification of Functioning, Disability and Health in routine practice: Lessons from a pilot study in China. J Rehabil Med 2016;48:502-7.

39. Li J. ICF Clinical Data Collection Tool. The Chinese Experience. Poster session presented at: UEMS-PRM Section and Board Workshop. 2016 Jan 22-23; Nottwil, Switzerland.

40. Boldrini P, Gimigliano F. ICF Clinical Data Collection Tool. The Italian Experience. Poster session presented at: UEMS-PRM Section and Board Workshop. 2016 Jan 22-23; Nottwil, Switzerland.

41. Selb M, Gimigliano F, Stucki G, Boldrini P. Building the road toward an International Classification of Functioning, Disability and Health Clinical Data Collection Tool: The Italian experience of developing simple, intuitive descriptions of ICF Rehabilitation Set categories. [Manuscript submitted].

42. Haigh R, Tennant A, Biering-Sorensen F, Grimby G, Marincek C, Phillips S, et al. The use of outcome measures in physical medicine and rehabilitation within Europe. J Rehabil Med 2001;33:273-8.

43. Tennant A. Considerations for updating evidence on assessment tools currently used in Europe. Poster session presented at: UEMS-PRM Section and Board Workshop. 2016 Jan 22-23; Nottwil, Switzerland.

44. Prodinger B, Tennant A, Stucki G, Cieza A, Ustün TB. Harmonising routinely collected health information for strengthening quality management in current health systems: Requirements and practice [In press]. J Health Serv Res Policy 2016.

45. Lavis JN, Oxman AD, Moynihan R, Paulsen EJ. Evidence-informed health policy 1 - Synthesis of findings from a multi-method study of organizations that support the use of research evidence. Implement Sci 2008;3:53

46. Lavis JN, Paulsen EJ, Oxman AD, Moynihan R. Evidence-informed health policy 2 - Survey of organizations that support the use of research evidence. Implement Sci 2008;3:54.

47. Lavis JN, Oxman AD, Moynihan R, Paulsen EJ. Evidence-informed health policy 3 - Interviews with the directors of organizations that support the use of research evidence. Implement Sci 2008;3:55.

48. Lavis JN, Moynihan R, Oxman AD, Paulsen EJ. Evidence-informed health policy 4 - Case descriptions of organizations that support the use of research evidence. Implement Sci 2008;3:56.

Conflicts of interest.-The authors certify that there is no conflict of interest with any financial organization regarding the material discussed in the manuscript. Acknowledgments.-The authors of this report would like to acknowledge the contribution of the participants of the Nottwil workshop: UEMS PRM delegates: Carlotte Kiekens, Belgium; Karel Moses, Czech Republic; Andreas Winkelmann, Germany; Anda Nulle, Latvia; Ingebjørg Irgens, Norway; Helena Burger, Slovenia; Rolf Frischknecht, Switzerland; Enrique Varela Donoso, Spain; Ayșe Küçükdeveci and Aydan Oral, Turkey, Henk Stam, the Netherlands; ISPRM: Francesca Gimigliano, Christoph Gutenbrunner; SIMFER: Paolo Boldrini and Maurizio Massucci; SGPMR: Michael Baumberger, Inés Kramers and Graziano Ruggieri; ICF Research Branch: Reuben Escorpizo, Birgit Prodinger; Swiss Paraplegic Research: Cristiana Baffone, Carolina Ballert, Mirjam Brach, Per von Groote, Andrea Rebsamen and Alan Tennant; Swiss Paraplegic Center: Hans Peter Gmünder, Patricia Lampart, Anke Scheel-Sailer and Klaus Schmitt; Experts/Observers: Dominique Van de Velde, Belgium; Thorsten Meyer, Germany; Iuly Treger, Israel; Aivars Vetra, Latvia; Vincenzo della Mea, Italy; Claudio Rumiano, Italy; Chiara Pagliari, Italy; Masahiko Mukaino, Japan; Eriks Svede, Latvia; Julija Vasilevska, Latvia; Cecilie Røe, Norway; José Maria Tormos Muños, Spain.

The authors would also like to thank Melissa Selb, Sara Rubinelli, Jerome Bickenbach, Alessandro Giustini and Susanne Stucki for their critical review and comments on drafts of this report.

Article first published online: November 24, 2016. 